\title{
THE EFFECT OF CHLORDANE AND THIRAM ON DAMPING-OFF AND SEEDLING GROWTH ${ }^{1}$
}

\section{BY J. COCKERILL ${ }^{2}$ \\ $A B S T R A C T$}

Chlordane, applied to seed beds of red pine to control white grub infestation, increased seedling mortality due to damping-off in these beds. Losses were significantly reduced when the seed was pelleted with thiram prior to sowing. Neither chlordane nor thiram, alone or in combination, had any apparent adverse effect on seedling growth, root development, or the formation of mycorrhiza.

\section{INTRODUCTION}

Considerable damage may be caused to seedling stock in forest tree nurseries by June beetle larvae (Phyllophaga spp.) feeding on the roots of seedlings (Craighead, 1950, Stoeckeler and Jones, 1957). These losses are generally heaviest in 1-year-old seedlings, but 2- and 3-year-old trees are also attacked.

Various cultural practices, including deep tilling and clean cultivation, are often used as control measures against white grub infestations (Craighead, 1950). However, the effectiveness and relative ease of application of the newer organic insecticides has led to the increased use of these materials in the pest control programs of many forest tree nurseries (Stoeckeler and Jones, 1957).

At the Midhurst Nursery of the Ontario Department of Lands and Forests chlordane has been used to treat seed beds and transplant compartments infested with white grub. For several years prior to 1955 chlordane had been applied to various seed bed areas and there had been no report of a detrimental effect due to this treatment. In 1955, however, exceptionally heavy losses due to damping-off occurred in a seed bed compartment which had been treated with chlordane the previous year. While these losses may have been due to unfavorable environmental factors, such as excessive soil moisture and warm weather, there was the possibility that the chlordane treatment had been a factor contributing to the heavy mortality reported in 1955.

An experiment to investigate the effect of chlordane on the incidence of damping-off was carried out at the Midhurst Nursery in 1956. The experimental design included the chlordane treatment and seed treatment. The seed treatment was a pellet of thiram, a fungicide which had effectively reduced dampingoff losses in other nurseries (Berbee et al., 1953, Cockerill, 1954).

The combination of the chlordane and thiram treatments provided a comparison of damping-off losses between soil treated with chlordane and un-

\footnotetext{
${ }^{1}$ Contribution No. 765, Forest Entomology and Pathology Branch, Department of Forestry, Ottawa, Canada.

${ }^{2}$ Laboratory of Forest Pathlogy, Southern Research Station, Maple, Ontario. For author's biography see For. Chron. 33(3), 1957.

${ }^{8}$ Adamson, M. A. Formerly Superintendent, Midhurst Nursery. Present address-District Forester, Parry Sound, Ontario-personal communication.
} 
treated soil, between seed treated with a fungicide and untreated seed, and between the treated and untreated seed in chlordane-treated and untreated soil. It was also possible to examine the effect on seedling development of the two biocides, which have both been shown capable, under certain conditions, of causing abnormal development of the roots and shoots of seedlings (Persidsky and Wilde, 1955). These biocides, in combination with allyl alcohol, have also been shown to affect the survival and behaviour of mycorrhizal fungi (Persidsky and Wilde, 1960).

\section{METHODS}

A seed bed compartment which had not received any previous chlordane treatment was used for the experiment. The experimental design included the following 8 treatments, located in a random pattern and replicated 4 times: 1) untreated soil, untreated seed;2),3), and 4) untreated soil and seed pelleted with thiram at the rate of 4,6 , and 8 ounces respectively per pound of seed; 5 ) chlordane-treated soil, untreated seed; 6), 7), and 8) chlordane-treated soil and seed pelleted at the same rate as in 2), 3), and 4). The chlordane treatment was applied at the rate of 2 gallons of 50 per cent emulsion per acre, the rate normally used by the Nursery. The application was made in the fall of 1955 , two weeks prior to sowing the seed.

Seedling mortality was recorded from sample areas within the various treatments for the period June 5 to July 9. A final count of the surviving seedlings, plus the mortality, gave the seedling emergence for each sample area.

Seedlings were examined for growth differences in the fall of 1956 and again in the fall of 1957 . While it was not possible to remove the entire root system of the seedlings, a reasonable and comparable amount was obtained when the samples were removed. Measurements were made of needle and stem length, while the development of the root system and the abundance of mycorrhizae were also noted. Microtome sections were made of the mycorrhizal rootlets for subsequent microscopic examination.

\section{Analysis of data}

\section{REsults}

The seedling mortality for the period June 5 to July 9 and the total emergence within the sample areas of the various treatments are given in Table 1.

A summary of the analysis of variance of the mortality data is given in Table 2. In this analysis three comparisons were shown to be significant. These were: 1) between chlordane-treated soil and untreated soil, 2) between thiram-

TABLE 1

Total Emergence, Mortality, and Survival for UNPelleted and Thiram-Pelleted Seed in Untreated Soil and Chlordane-Treated SoIl

\begin{tabular}{|c|c|c|c|c|}
\hline & \multicolumn{2}{|c|}{ No chlordane } & \multicolumn{2}{|c|}{ Chlordane } \\
\hline & unpelleted & pelleted & unpelleted & pelleted \\
\hline Emergence & \multicolumn{4}{|c|}{ Nambers of seedlings } \\
\hline Mortality & 432 & 439 & 1086 & 534 \\
\hline Survival & 1098 & 1830 & 897 & 1849 \\
\hline
\end{tabular}


TABLE 2

ANALYSis of VARIance For Mortality Data

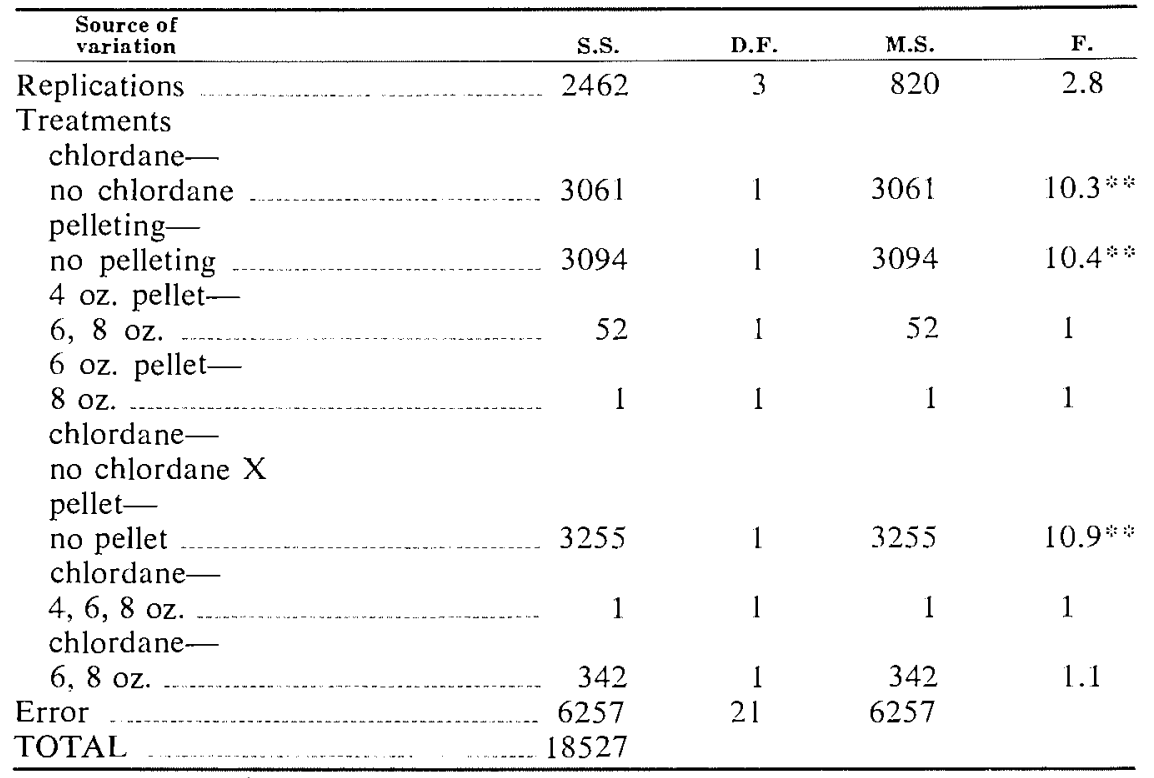

*: Significant at $1 \%$ level.

pelleted seed and unpelleted seed and 3 ) between thiram-pelleted and unpelleted seed in chlordane-treated and untreated soil. For the emergence data a significant difference was shown between seed pelleted with thiram and unpelleted seed. (Table 3).

\section{Examination of Seedling Material}

There were differences between the average measurements of the stems and needles of the seedlings taken from the various treatments, but these were not great enough to indicate that either the chlordane or thiram treatments alone or in combination had any adverse effect on the stem or needle growth.

The mycorrhizal development of seedlings from the treated soil and pelleted seed was similar in form and abundance to that of seedlings which were not treated with these chemicals (Fig. 1). No malformation or cellular disorganization was revealed by microscopic examination of the mycorrhizal rootlet sections.

\section{Discussion}

Since the application of chlordane caused an increase in seedling mortality in the experimental area, a similar result could be expected from the use of this insecticide on other areas of the nursery. It would be reasonable to assume, therefore, that the seedling losses reported in 1955 were due to the application of chlordane to the seed beds, and that excessive losses might be expected whenever chlordane was applied, whether at Midhurst or at other nurseries.

Although the application of chlordane has been shown to cause an increase in seedling mortality, this should not preclude its use in the nursery management 

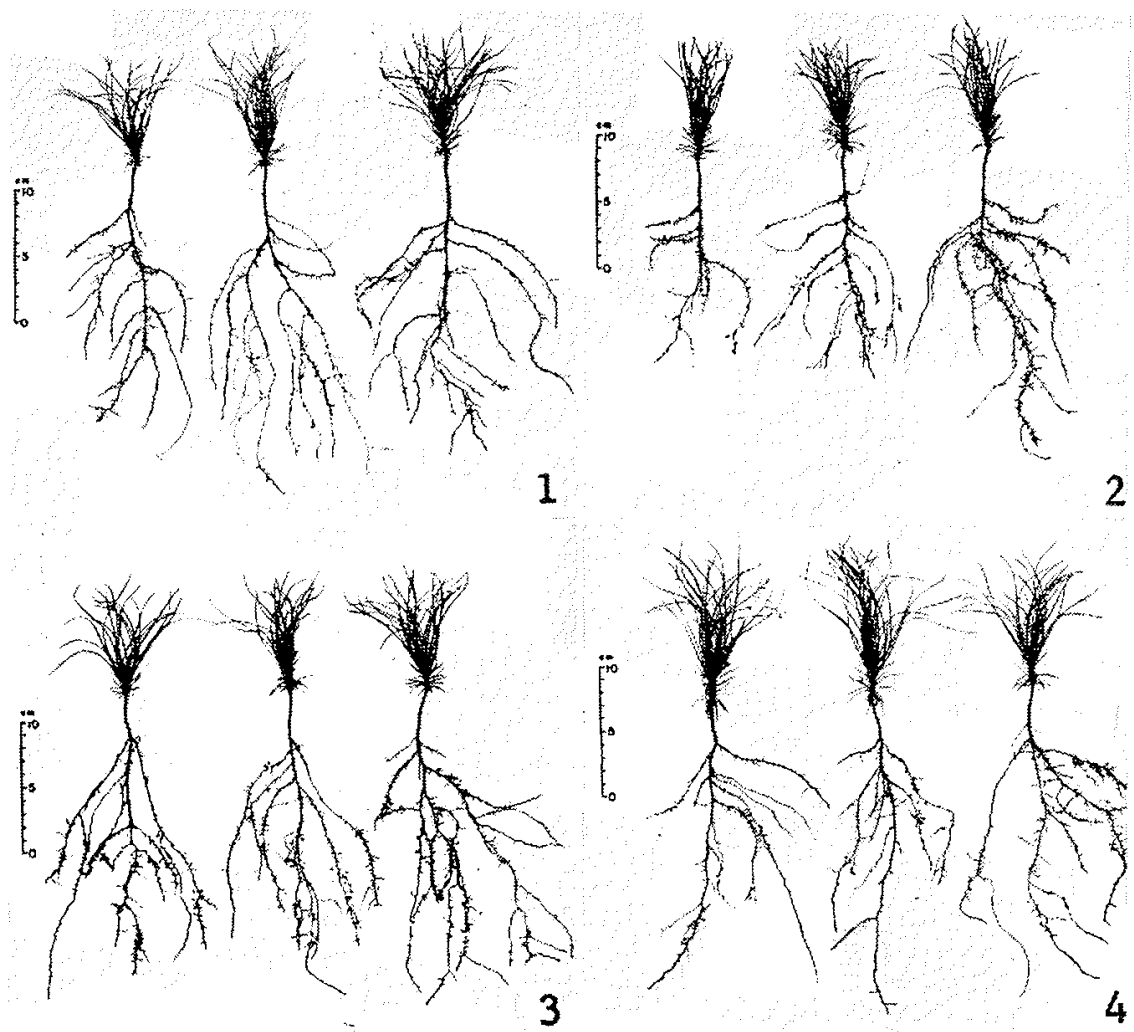

Photographs by Miss J. F. Robinson.

FIGURE 1. A comparison of seedlings from different treatments at the end of the first growing season.

1. Untreated soil, unpelleted seed.

2. Untreated soil, thiram-pelleted seed ( $8 \mathrm{oz}$. per lb.).

3. Chlordane-treated soil (2 gallons 50 per cent emulsion per acre), unpelleted seed.

4. Chlordane-treated soil (2 gallons 50 per cent emulision per acre), pelleted seed (8 oz. per lb.).

program since damping-off losses may be effectively controlled by the use of thiram, or other fungicides, applied as a pellet or to the soil (Cram and Vaartaja, 1957).

The use of biocides in the nursery management program would be of little value if they produced abnormal growth symptoms on the seedlings. However, the irregular growth effects attributed to various eradicants (Persidsky and Wilde, 1955 and 1960) were not apparent on the seedlings in any of the treatments in this investigation.

It has been reported that the adverse effects of biocides may be modified by the colloidal material present in the soil and that the addition of organic 
TABLE 3

ANALysis of VARIANCE FOR EMERgence DATA

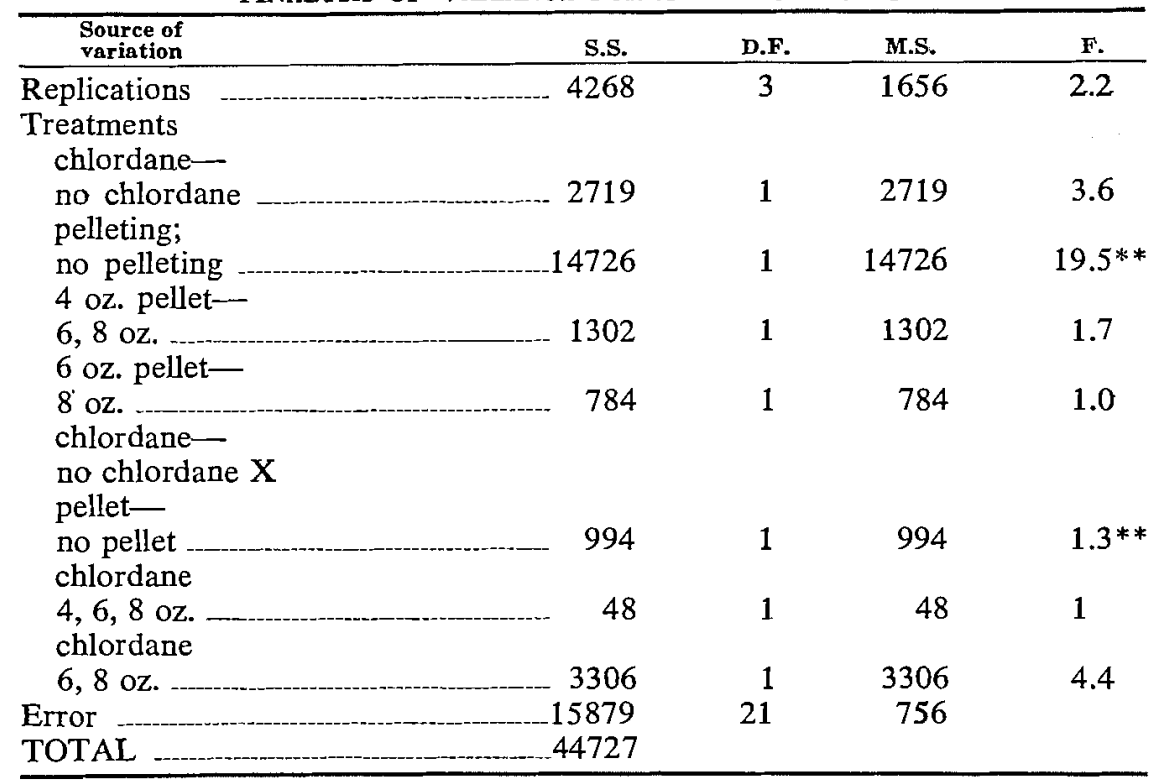

* Significant at $1 \%$ level.

matter will provide an ameliorating effect in biocide-treated soils (Persidsky, 1957). Organic matter may be added to soil through the addition of peat, sawdust, or crop residues. At the Midhurst Nursery it is the practice to add organic matter to the soil by incorporating green manures and peat into the soil. Apparently, based on the results of this investigation, the amount of organic material added in this way has been sufficient to buffer the harmful effects of the biocides used in this experiment.

Since most forest tree nurseries provide for the addition of organic matter in their soil management programs, the organic content of these soils should be sufficient to buffer the potentially harmful effects of biocide treatments. It is felt, therefore, that the use of chlordane as an insecticide for controlling white grub infestations might be recommended as an effective method for use in tree nurseries. It is suggested, however, that the minimum recommended dosage be used and that protection be provided against damping-off losses which could be expected to occur in the treated seed beds.

\section{ACKNOWLEDGEMENTS}

The author wishes to thank Mr. Adamson for providing the facilities for carrying out this investigation and Mr. L. M. Morrison, Statistician, Reseach Branch, Ontario Department of Lands and Forests (now with Ontario Department of Transport) who provided the design and completed the statistical analysis. 


\section{REFERENCES}

BERBEE, J. G., BERBEE, FLORA and W. H. BRENNER. 1953. The prevention of dampingoff of coniferous seedlings by pelleting seed. (Abst.), Phytopathology 43: 466.

COCKERILL, J. 1954. Studies in the control of damping-off of red pine-Provincial Forest Nursery, Orono, Ont. Interim Report. For. Path. Lab., Maple, Ont.

CRAIGHEAD, F. C. 1950 . Insect enemies of eastern forests. U.S.D.A. Misc. Pub. No. 657.

CRAM, W. H. and O. VAARTAJA. 1957. Rate and timing of fungicidal soil treatments. Phytopathology 47: 169-173.

PERSIDSKY, D. J. 1957. Mineral colloids modify the effects of eradicants. Unip. of Wisc. For. Res. Note No. 32.

PERSIDSKY, D. J. and S. A. WILDE. 1955. Effect of eradicants on the microbiological properties of nursery soils. Wisc. Academy of Sci., Arts, and Letters. 44: 65-73.

PERSIDSKY, D. J. and S. A. WILDE. 1960. The effect of biocides on the survival of mycorrhizal fungi. Jour. For, 58: 522-524.

STOECKALAR, J. H. and G. W. JONES. 1957. Forest nursery practice in the Lake States. U.S.D.A. Handbook No. 110. 